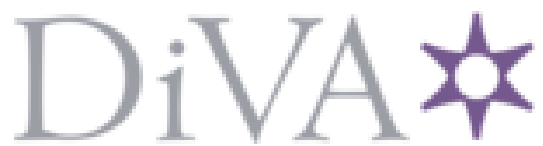

http://www.diva-portal.org

This is the published version of a paper published in .

Citation for the original published paper (version of record):

Mukesh, C., Nikjoo, D., Mikkola, J-P. (2020)

Production of C-14 Levulinate Ester from Glucose Fermentation Liquors Catalyzed by Acidic Ionic Liquids in a Solvent-Free Self-Biphasic System

ACS Omega, 5(10): 4828-4835

https://doi.org/10.1021/acsomega.9bo3517

Access to the published version may require subscription.

N.B. When citing this work, cite the original published paper.

Permanent link to this version:

http://urn.kb.se/resolve?urn=urn:nbn:se:umu:diva-168744 


\title{
Production of C-14 Levulinate Ester from Glucose Fermentation Liquors Catalyzed by Acidic lonic Liquids in a Solvent-Free Self- Biphasic System
}

\author{
Chandrakant Mukesh,* Dariush Nikjoo, and Jyri-Pekka Mikkola* \\ Cite This: ACS Omega 2020, 5, 4828-4835 \\ Read Online
}

ACCESS | Lلll Metrics \& More | 国 Article Recommendations ｜（s Supporting Information

ABSTRACT: Herein, we present the C-14 levulinate ester of 2,3-butanediol as the product of sugar fermentation liquors. The designed Brønsted acidic ionic liquid (BAIL) catalysts enable self-induced phase separation with ester products, and the role of anions has been investigated. Esterification reactions were carried out by 2,3-butanediol (2,3-BDO) and levulinic acid in solvent-free media and low temperatures $\left(60-105^{\circ} \mathrm{C}\right)$. For comparison, sulfuric acid, amberlite IR-120, and sulfonic acid-functionalized pyridinium ionic liquids with different anions were utilized as a catalyst upon esterification reaction. The diester product, namely, butane-2,3-diyl bis(4-oxopentanoate), was formed with a good yield (85\%) and selectivity (85\%) after complete conversion of $2,3-\mathrm{BDO}$ in $24 \mathrm{~h}$ at $80{ }^{\circ} \mathrm{C}$. The low yield ( $8 \%$ ) of the monoester was observed. The monoester and diester were separated by a liquid-liquid extraction method. The ester products were characterized by various instrumental techniques such as ${ }^{1} \mathrm{H}$ and ${ }^{13} \mathrm{C} \mathrm{NMR}, \mathrm{GC}-$

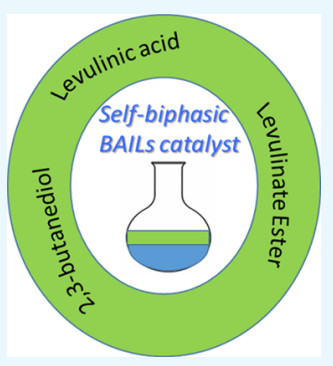
FID, LC-MS, and FT-IR spectroscopy. The Hammett acidity functions of BAILs were determined from UV-vis spectroscopy. The catalyst was successfully recycled and reused in the processes. The spent BAILs were reused in six consecutive cycles with only a $\sim 7 \%$ diminished diester yield and selectivity. The produced levulinate ester will be useful as biofuel additives, solvents, plasticizers, and other applications.

\section{INTRODUCTION}

The levulinate ester and oxygenated biofuels derived from biomass are inspiring as potentially sustainable and green products obtained via green processes. Levulinate ester and oxygenated biofuels are demonstrated as potential fuel additives and compounds that are able to reduce the emission of greenhouse gases. ${ }^{1-3}$ One of them, levulinic acid (LA) based ester, is a potential green chemical produced from cellulose at an industrial scale, namely, in the "biofine process" catalyzed by sulfuric acid. ${ }^{4}$ On the other hand, 2,3-BDO is obtained from the fermentation liquors of sugars (glucose and xylose). ${ }^{5}$ The 2,3-BDO biomolecule is mainly produced by hydrolysis of 2,3-epoxybutane at an industrial scale. This, in turn, is used as a precursor in the manufacture of a range of chemical products, including solvents such as methyl ethyl ketone, gamma-butyrolactone, and their ester to produce 1,3butadiene. $^{6-8}$ The esterification reaction of LA with methanol to higher chain alcohols has been demonstrated over various homogeneous and heterogeneous catalysts and the ester can have use in a range of applications such as biofuel additives, fragrances, cosmetic products, plasticizers, solvents, and a range of material formations. ${ }^{3,9-14}$ Texaco tested blending of $20 \%$ ethyl levulinate, $79 \%$ diesel, and $1 \%$ of other coadditives in diesel engines and the results indicated reduced sulfur and $\mathrm{NO}_{x}$ emissions. ${ }^{15,16}$ Moreover, good improvements in the physical properties such as cold point (CP), pour point, and cold filter plugging points as well as low kinematic viscosity were found. ${ }^{17}$ The blending of levulinate ester or fatty acid ester in diesel also reduced the $\mathrm{NO}_{x}$ and $\mathrm{SO}_{x}$ emissions. ${ }^{18,19}$ The shortest alkyl chain, methyl levulinate is a potential gasoline additive. The higher alkylated levulinates have a better solubility in aromatics-rich diesel range fuels and biodiesel. ${ }^{20,21}$ The boiling point of ethyl levulinate and longer chain levulinate have similar boiling points to the heavy gasoline compounds $(475 \mathrm{~K})$ or middle diesel fuel boiling range. ${ }^{22}$ They neither significantly alter the volatility nor require any modification to the existing diesel engine upon their blending with diesel. ${ }^{21}$

Upon esterification, processes have been promoted by strong acids like $\mathrm{H}_{2} \mathrm{SO}_{4}, \mathrm{HCl}$, para-toluenesulfonic acid, Brønsted acidic ionic liquids (BAILs), and heterogeneous catalysts. $^{23-25,27}$ However, overcoming the disadvantages of mineral acids such as product separation, high corrosion rate, reusability, and difficulties in handing require an alternative catalyst. Alternatively, BAILs are potential candidates and were investigated in chemical synthesis as greener catalysts and environmentally benign alternatives. ${ }^{24}$ BAILs with $\left[\mathrm{HSO}_{4}\right]$ anions and functionalized sulfonic acid ionic liquids (ILs) has been found to be less corrosive compared to sulfuric acid. ${ }^{25,26}$

Received: October 21, 2019

Accepted: February 19, 2020

Published: March 2, 2020 
Table 1. Oxygenated Biofuel Additives

\begin{tabular}{|c|c|c|}
\hline oxygenated biofuel additives & carbon no. & refs \\
\hline 2-nonanone, nonanal, nonanal dimethyl acetal, methyl nonanoate & C-9 to $\mathrm{C}-11$ & 1 \\
\hline furan derivatives (2-methyltetrahydrofuran, dimethlfuran, 2,5-bis(ethoxymethyl)furan, and so forth) & C-6 to $\mathrm{C}-10$ & 2 \\
\hline triacetin & C-9 & 35 \\
\hline propane-1,2,3-triyl tris(4-oxopentanoate) & $\mathrm{C}-18$ & 33 and 34 \\
\hline ethyl levulinate & $\mathrm{C}-7$ & 15 \\
\hline butane-2,3-diyl bis(4-oxopentanoate) & $\mathrm{C}-14$ & present work \\
\hline
\end{tabular}

Heterogeneous catalysis is always preferred in terms of easy product separation, catalyst reusability, temperature sustainability, and selective product formation. However, in order to operate, heterogeneous catalysts typically require high temperature owing to their lower reactivity. Catalyst deactivation by carbon deposition is a major obstacle compared to the homogeneous catalysts. Multifunctional molecules are not suitable when operating at high-temperatures because of the formation of many byproducts. Also, byproduct separation is another tedious task to obtain the desired, pure product. Therefore, systems that operate at low temperatures and biphasic systems are the most promising way to perform chemical transformations, particularly in the presence of water (or in situ formation of water). In this regard, IL catalysts are potentially most effective, thermally stable, low volatile, nonflammable, reusable, and highly reactive similar to the homogeneous catalysts. ${ }^{24,27}$ The advantages of biphasic IL catalysts are easy product separation, lower temperature reaction, easy catalyst recycle, and efficiency in repeated cycles. Recently, Riisager et al. reported the synthesis of ethyl levulinate from mono and disaccharides using sulfonic acidfunctionalized ILs as catalysts. ${ }^{27}$ Han et al. reported halogenfree Brønsted-Lewis acidic IL catalysts for esterification upon synthesis of methyl caprylate. ${ }^{28}$ The biphasic system induced separation of ester products with the help of heteropolyanionbased ILs. ${ }^{23}$ However, HPAs are costly materials. Recently, alkyl imidazolium hydrogen sulfate was demonstrated as a selfinduced biphasic system upon butyl levulinate production with 98.1\% yield and selectivity. ${ }^{29}$ Also, the suitably designed BAILs were used as a biphasic reaction media for the long-chain ester (wax ester, yield 99\%) synthesis in a solvent-free media. ${ }^{30}$ However, few ester products of 2,3-BDO have been reported with monobasic acids or their functional equivalents. ${ }^{6,31}$ The esterification of 2,3-BDO with formic acid and acetic acid catalyzed by $\mathrm{H}_{2} \mathrm{SO}_{4}$ and the diester yields were found to be 70 and $85 \%$, respectively. ${ }^{6}$ Jacquin et al. studied the kinetics of esterification of 2,3-BDO with acetic acid over a heterogeneous catalyst (Amberlyst 36). ${ }^{32}$ Further, upon esterification of LA with glycerol, the diacylglycerides became the major products at a reaction temperature of $140{ }^{\circ} \mathrm{C}$ with $85 \%$ selectivity over Al-SBA-15 as the heterogeneous catalyst. ${ }^{33}$ The esterification of glycerol with LA gives new opportunities in terms of highly oxygenated biofuel additives. ${ }^{34}$ Similarly, triacetin improved the physical properties of the fuel like CP and viscosity after blending in biodiesel. ${ }^{35}$ Therefore, biomass-based renewable alcohols and carboxylic acids are promising oxygenated biofuel additives among other applications.

Herein, we for the first time report the new types of biomolecules, namely, butane-2,3-diyl bis(4-oxopentanoate) as a diester and 3-hydroxybutan-2-yl 4-oxopentanoate as a monoester. The esterification reaction between 2,3-BDO and LA catalyzed by Brønsted ILs gives rise to self-induced phase separation. The reaction was performed in a solvent free media at low temperatures $\left(80^{\circ} \mathrm{C}\right)$ whereupon good yield $(85 \%)$ and selectivity $(85 \%)$ was obtained. In comparison, similar yields and selectivities of diester were observed as per previous reports over both homogeneous and heterogeneous catalysts. Recycled ILs were reused multiple times in the processes with slightly deteriorating chemical activity. The diester and monoester were separated with the liquid-liquid extraction method.

\section{RESULT AND DISCUSSION}

The prepared C-14 levulinate ester could be useful as biofuel additives and in other applications. Several other levulinate esters and oxygenated biofuel additives have been proposed as suitable fuels for diesel engines. Some oxygenated biofuel additives are summarized in Table 1 . We are introducing C-14 levulinate ester of 2,3-butanediol with LA, namely, butane-2,3diyl bis(4-oxopentanoate). We expect that the physicochemical properties and other parameters of the prepared levulinate ester are suitable for blending in diesel fuels. Advances in the development of biofuel additives from renewable resources promote the transfer from fossil to alternative sources of transportation fuels.

2.1. Characterization of Products. The purified products, diester and monoester were characterized by ${ }^{1} \mathrm{H}$ and ${ }^{13} \mathrm{C}$ NMR and Fourier transform infrared (FT-IR) spectroscopy. The NMR spectra of butane-2,3-diyl bis(4-oxopentanoate) as a diester of 2,3-BDO with LA are given in Figure 1. The proton peak of $-\mathrm{COO}-\mathrm{CH}-$ appears at $4.94 \mathrm{ppm}$ of the diester. The proton shifted to $-\mathrm{CH}_{3}(\sim 0.1)$ form the original position and proton peaks of $-\mathrm{OH}$ and $-\mathrm{CH}-$ of 2,3-BDO vanished after complete esterification. ${ }^{13} \mathrm{C}$ NMR revealed that the new peak that appeared at $172.16 \mathrm{ppm}$ was found to correspond to ester carbon peaks (-COO-) and the disappeared carboxylic functional group peak of LA from $178.41 \mathrm{ppm}$ (Figure S2b,d). Hereupon, the diester product was confirmed. Meanwhile, partial esterification of 2,3-BDO forms the monoester, the proton peak of $-\mathrm{COO}-\mathrm{CH}-$ appears at $4.88 \mathrm{ppm}$, and a small shift $(\sim 0.2 \mathrm{ppm})$ of the $-\mathrm{CH}-\mathrm{O}-$ proton. The ${ }^{1} \mathrm{H}$ NMR of monoester, 2,3-BDO and LA are given in Figure S1. Two different methyl protons (two doublet) were also observed because of different chemical environments (Figure S1c). Similarly, ${ }^{13} \mathrm{C}$ NMR of the monoester -COO- peak observed at $172.64 \mathrm{ppm}$ and four different peaks were observed after monoester formation (Figure S2c). FT-IR spectra revealed the ester formation of LA with 2,3-BDO, which are shown in Figure S3. The broad peak of $\mathrm{O}-\mathrm{H}$ stretching of 2,3-butanediol and the monoester was detected at 3338 and $3446 \mathrm{~cm}^{-1}$, respectively. The strong carbonyl stretching of ketone, carboxylate, and acidic functional groups was observed in the range of $1700-1738 \mathrm{~cm}^{-1}$. After the higher magnification of carbonyl peak, all three peaks were differentiated from each other (Figure 2). In the IR spectra of $\mathrm{LA}$, the peak at 1701 and $1737 \mathrm{~cm}^{-1}$ corresponds to $\mathrm{C}=\mathrm{O}$ 


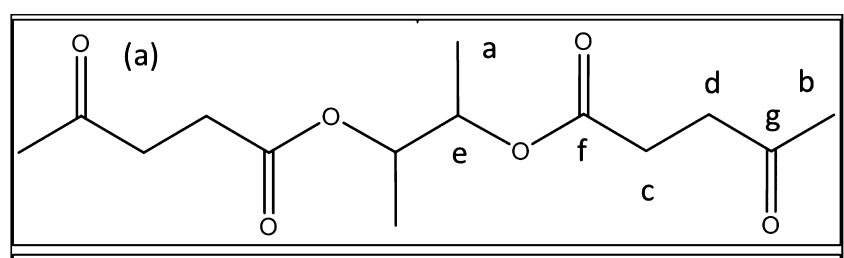

(b)
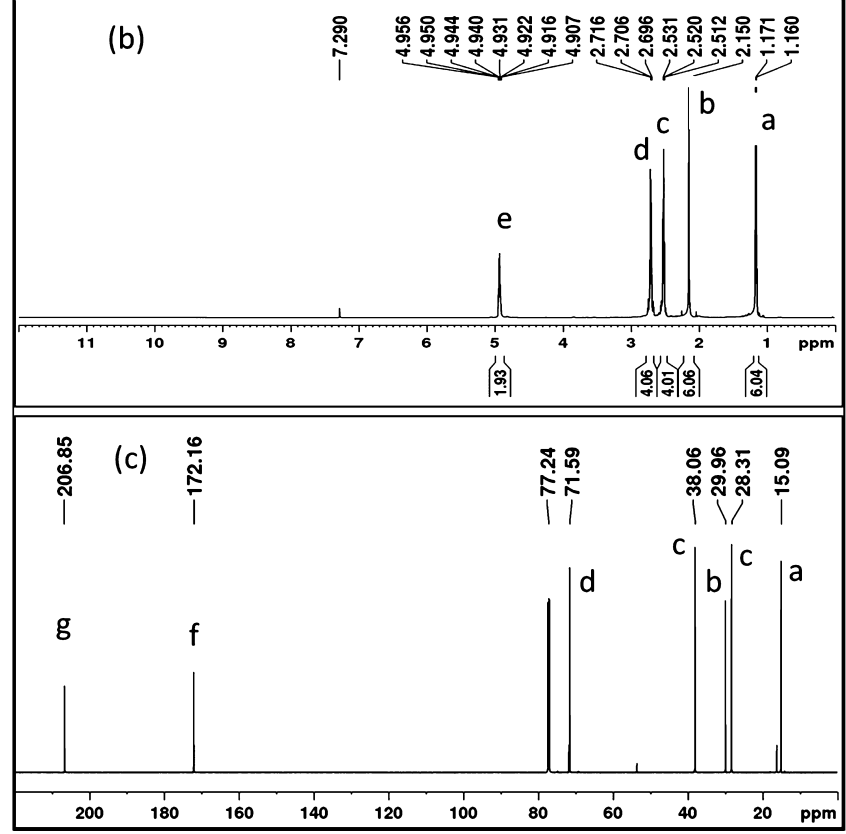

Figure 1. (a) Molecular structure, (b) ${ }^{1} \mathrm{H}$ NMR, and (c) ${ }^{13} \mathrm{C}$ NMR of butane-2,3-diyl bis(4-oxopentanoate).

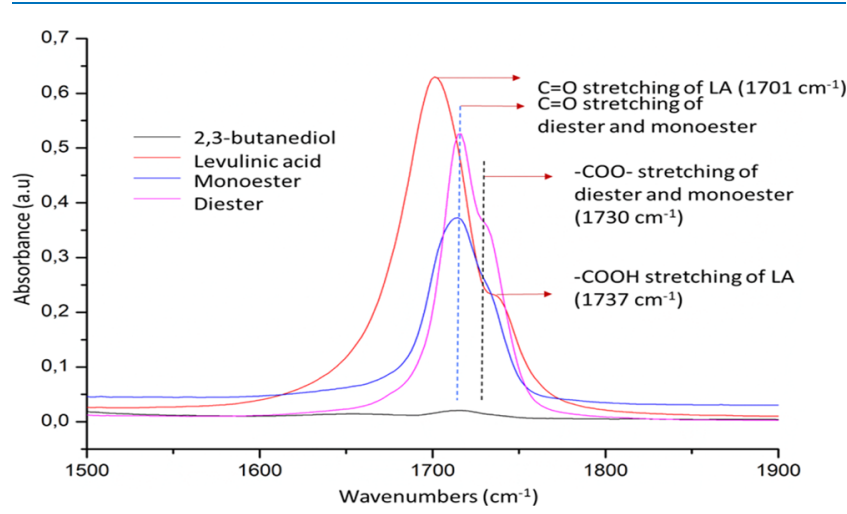

Figure 2. FT-IR of carbonyl stretching of LA, monoester, and diester.

stretching of ketone and carboxylic acid functional groups, respectively. The $\mathrm{C}=\mathrm{O}$ stretching of carboxylate detected at 1730 and $1732 \mathrm{~cm}^{-1}$ of the diester and monoester (Figure 2). This advocated the esterification reaction. However, in the ester products, $\mathrm{C}=\mathrm{O}$ stretching of ketone functional groups shifted from 1701 to 1716.5 and $1714.6 \mathrm{~cm}^{-1}$ in the diester and monoester. The $\mathrm{O}-\mathrm{H}$ stretching completely vanished after diester formation. The $\mathrm{C}-\mathrm{O}$ stretching of 2,3-BDO and LA were detected at 1055 and $1159 \mathrm{~cm}^{-1}$. However, in the case of the diester, $\mathrm{C}-\mathrm{O}$ was detected at $1155 \mathrm{~cm}^{-1}$ (Figure S3). The calibration curves were obtained using different concentrations of purified products (Figure S4). The molecular ion $(\mathrm{m} / \mathrm{z}$ ) of both the monoester and diester was confirmed by liquid chromatography-mass spectrometry (LC-MS) spectra. The $\mathrm{M}+1$ peak of the monoester and diester was obtained at 189.2 and 287.2 (Figure S5).
2.2. Esterification of 2,3-Butanediol and LA by $\mathrm{H}_{2} \mathrm{SO}_{4} /$ BAILs. Preliminary experiments were carried out at $105{ }^{\circ} \mathrm{C}$ by $\mathrm{H}_{2} \mathrm{SO}_{4} /$ BAILs $(0.57 \mathrm{mmol})$ with $2 \mathrm{gm}$ of LA and $0.78 \mathrm{gm}$ of 2,3-BDO (2,3-BDO:LA, 1:2 mole ratio) in a closed system. The product yields are summarized in Table S2. The BAILs-1, BAILs-2, and $\mathrm{H}_{2} \mathrm{SO}_{4}$ displayed similar catalytic behavior observed upon diester formation because of comparable Hammett acidity functions $\left(H_{\mathrm{o}}\right)$ (Table S2, Entry 1-4). Complete conversion of 2,3-BDO was observed. The ester products were formed with yields of around $50-60 \%$ only because of the formation of intermediates and byproducts. Also, the diester yields did not exceed $40-42 \%$ after increasing the reaction time from 4 to $6 \mathrm{~h}$, at $105^{\circ} \mathrm{C}$. BAILs- 3 gave rise to a poor yield of the diester (10\%) and monoester (23\%) at 105 ${ }^{\circ} \mathrm{C}$ after $6 \mathrm{~h}$ (Table S2, Entry 5). In the case of BAILs-4 ( $\mathrm{HSO}_{4}$ anion, $\left.H_{\mathrm{o}}=\sim 2.98\right)$, very low esterification levels were found (Table S2, Entry 6). The plausible reasons are that the Hammett acidity was low and a steric hindrance by a methyl group was present (double activation energy required). ${ }^{32}$ Similar results were also reported in case of esterification when higher $H_{\circ}$ value (low Brønsted acidity) compounds were utilized and lower yields of ester products formed in BAILs. ${ }^{36}$ For comparison with a heterogeneous catalyst, Amberlite IR120 (20 wt \% dry) was used. As a result, the diester yield was $35 \%$ (Table S2, Entry 7). The reason behind the low yield of ester products is that the equilibrium shifts. In fact, water hampers the forward reaction to the products (in situ generation). Therefore, we tried to continuously evaporate water during esterification reaction as well as increase the catalyst loading. After esterification, BAIL-2 gave rise to twophase separation and detailed studies with other BAILs were commenced. Herein, we selected BAIL-2 as the catalyst of choice for more detailed studies like catalyst loading, the influence of temperature, and the role of LA concentration to enhance the product yield and selectivity.

2.3. Catalyst Loading of BAIL-2. The catalyst loading of BAIL-2 was increased from 0.57 to $1.71 \mathrm{mmol}$ (3 times) and water was subjected to continuous evaporation at $105^{\circ} \mathrm{C}$ for 6 h. Even then, the maximum yield of diester $61 \%$ was reached after $6 \mathrm{~h}$ at $105^{\circ} \mathrm{C}$ with the same catalyst concentration $(0.57$ $\mathrm{mmol})$. In case of doubling the catalyst loading $(1.14 \mathrm{mmol})$, the diester yield was increased from 61 to $65 \%$ after complete conversion of 2,3-BDO (Figure 3A). Further increase in catalyst loading $(1.71 \mathrm{mmol})$ resulted in poorer yield and selectivity of the diester. To perceive the catalyst activity of other BAILs, more experiments were executed at this concentration (1.14 mmol) under identical conditions.

2.4. Catalyst Optimization for Esterification Reaction of 2,3-BDO with LA. The synthesized BAILs, $\mathrm{H}_{2} \mathrm{SO}_{4}(1.14$ $\mathrm{mmol}$ ), and Amberlite IR-120 (20 wt \% dry) were investigated at $105{ }^{\circ} \mathrm{C}$ in a reaction lasting for several hours. The maximum yield of esters are summarized in Figure 3B. In the presence of $\mathrm{H}_{2} \mathrm{SO}_{4}$, fast kinetics was observed and the diester yield reached $61 \%$ after $2 \mathrm{~h}$. BAIL-1 and BAIL-2 also performed well with fast kinetics. The maximum diester yields for BAIL-1 (58.4\%) and BAIL-2 (65\%) were observed at $4 \mathrm{~h}$. Surprisingly, BAIL-3 gave rise to the poorest yield and BAIL- 4 was even less effective as discussed earlier, even after $24 \mathrm{~h}$. Moreover, the performance of BAIL-3 and BAIL-4 was not much improved upon higher catalyst loading $(2.28 \mathrm{mmol})$ and the diester yields of around 16.6 and $23.4 \%$, respectively, were observed after $24 \mathrm{~h}$. In case of Amberlite IR-120 (20\% dry wt), a low diester yield (59\%) was observed after $24 \mathrm{~h}$. Further, we tried 

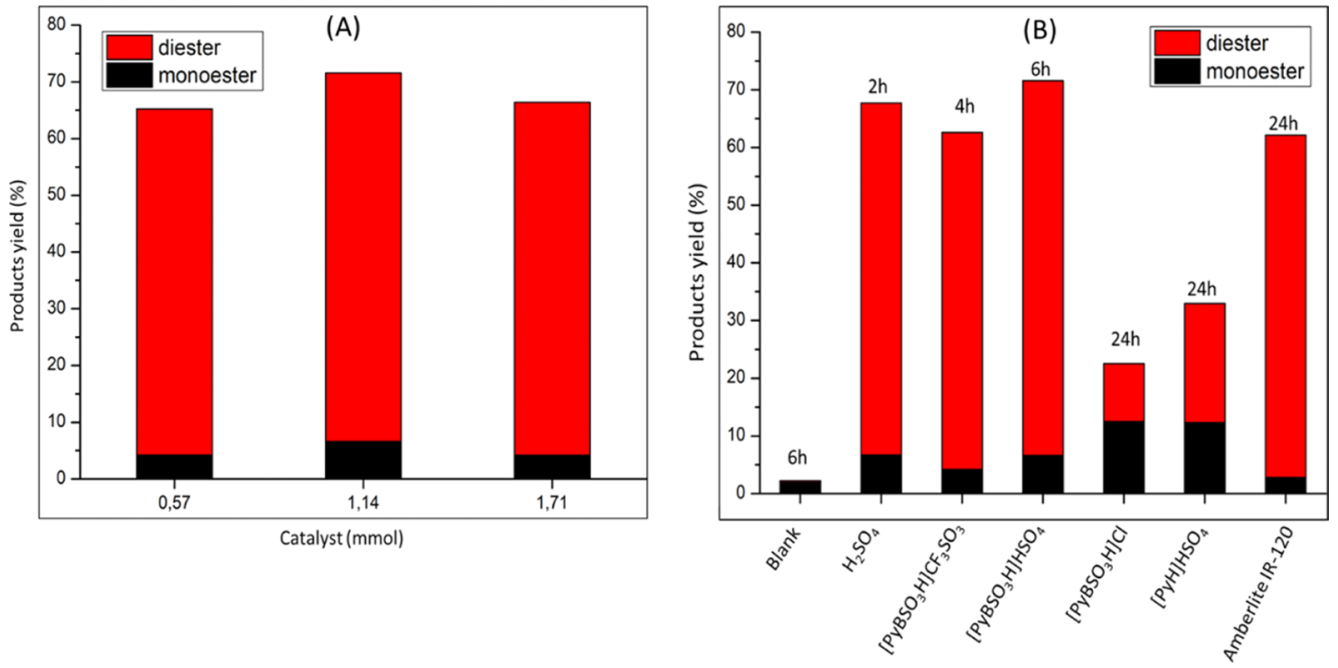

Figure 3. (A) Yield $( \pm 2 \%)$ of the diester and monoester with different catalyst loadings (mmol) of BAIL-2, at $105^{\circ} \mathrm{C}$ after $6 \mathrm{~h}$. The mole ratio of 2,3-BDO:LA (1:2) after complete conversion of 2,3-BDO, (B) maximum yield ( $\pm 2 \%)$ of esters over different catalysts at $105^{\circ} \mathrm{C}$ and the mole ratio of 2,3-BDO:LA (1:2) after complete conversion of 2,3-BDO.
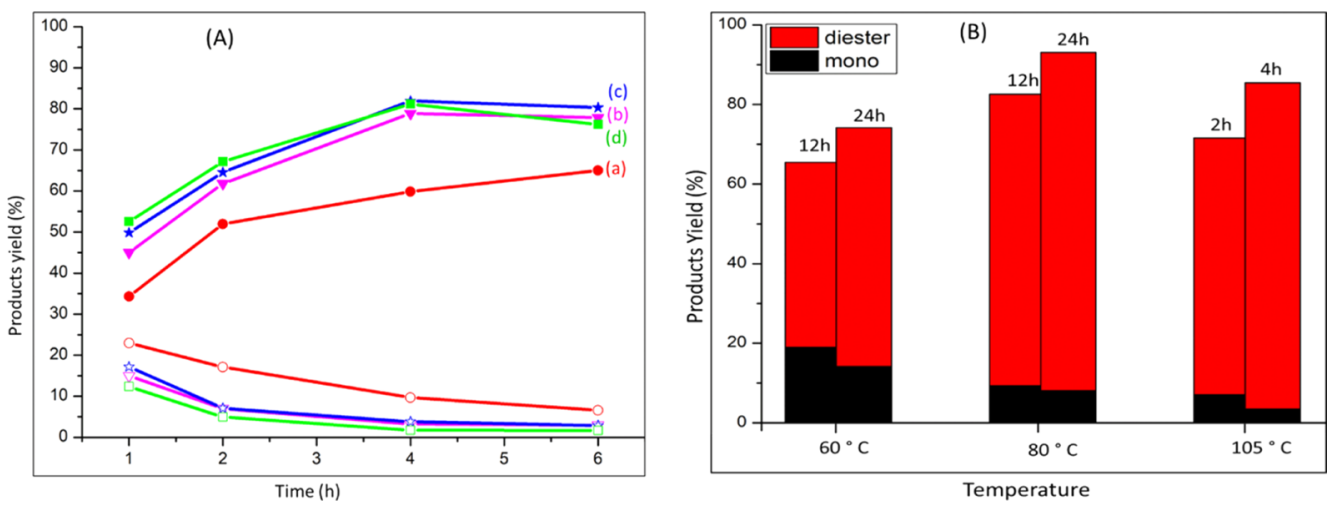

Figure 4. (A) Yield $( \pm 2 \%)$ of the diester (filled symbol) and monoester (open symbol) catalyzed by $\left[\mathrm{PyBSO}_{3} \mathrm{H}\right] \mathrm{HSO}_{4}(1.14 \mathrm{mmol})$ with varying the mole ratio of 2,3-BDO:LA (a) (1:2), (b) 1:2.5, (c) 1:3, and (d) $1: 4$ at $105{ }^{\circ} \mathrm{C}$ for several hours. (B) Yield ( $\pm 2 \%$ ) of products in the molar ratio of 2,3-BDA:LA (1:3) from 60 to $105{ }^{\circ} \mathrm{C}$ with $1.14 \mathrm{mmol}$ catalyst for various reaction times.
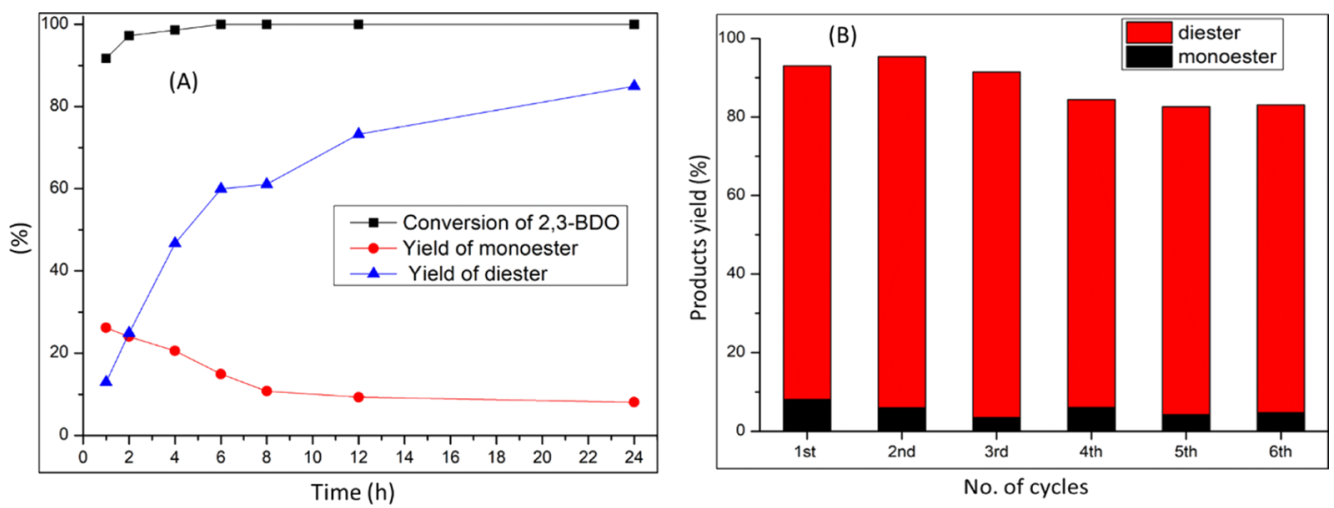

Figure 5. (A) Conversion $( \pm 1 \%)$ of $2,3-\mathrm{BDO}$ and yield $( \pm 2 \%)$ of esters in a molar ratio of 2,3 -BDA:LA $(1: 3)$ at $80{ }^{\circ} \mathrm{C}$ with 1.14 mmol BAIL-2, (B) yield $( \pm 2 \%)$ and selectivity $( \pm 2 \%)$ of ester products upon six consecutive catalytic cycles (BAIL-2 1.14 mmol) at a molar ratio of 2,3-BDA:LA $(1: 3)$ at $80{ }^{\circ} \mathrm{C}$.

to play with the LA concentration while maintaining the same temperature and chose BAIL-2 as the catalyst.

2.5. Influence of LA Concentration (Dilution Effect). At stoichiometric mole ratios bad diester selectivities were observed. Therefore, we experimented with shifting the equilibrium toward the product with $1.14 \mathrm{mmol}$ catalyst loading at $105{ }^{\circ} \mathrm{C}$. As a result, the diester yield and selectivity were enhanced from 65 to $77 \%$ when 3 moles of LA (excess) was used. The values represent concentrations at complete conversion of 2,3-BDO. The diester and monoester yields are summarized in Figure 4A. Similarly, the yield and selectivity of diester are reported for the case when four times excess LA was 


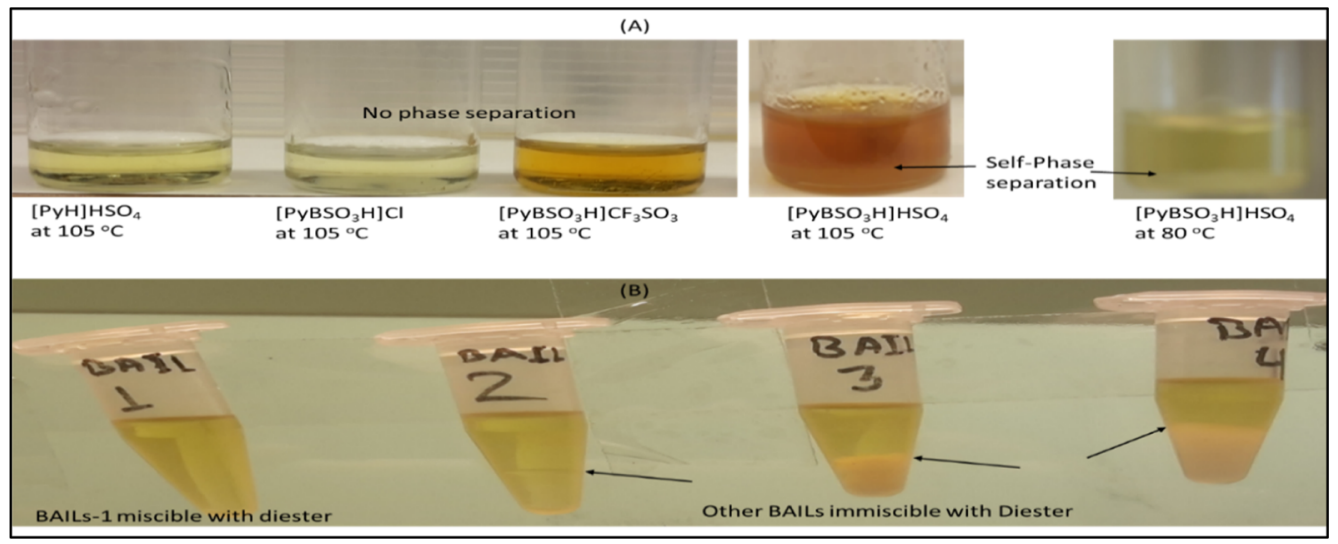

Figure 6. (A) Pictorial demonstration of phase separation of BAILs, (B) immiscibility of the catalyst with the diester product.

present at otherwise identical conditions. There are many possibilities of byproduct formation in the presence of strong acid and at high temperature, as previously reported. ${ }^{37,38}$ This could be the reason for low diester yields and selectivities. Therefore, achieving the highest yield and selectivity of the diester, low temperature esterification is necessary. The highest yields (diester $85 \%$ and monoester $8 \%$ ) were observed at low temperature $\left(80^{\circ} \mathrm{C}\right)$, at the complete conversion of 2,3-BDO $\left(24 \mathrm{~h}\right.$ at $80^{\circ} \mathrm{C}$, Figure $\left.4 \mathrm{~B}\right)$. The temperature plays a significant role upon esterification and faster esterification was observed at the higher temperature as depicted in Figure 4B. On decreasing the temperature from 105 to $60{ }^{\circ} \mathrm{C}$, slower rate of esterification was naturally observed. A low diester yield (60\%) was observed at $60{ }^{\circ} \mathrm{C}$ after $24 \mathrm{~h}$.

2.6. Conversion of 2,3-BDO and Catalyst Reusability. Initially, 2,3-BDO converted into an intermediate monoester and some diester as well as small amounts of byproducts were observed. Similar phenomena were observed at all three temperatures. Along with the time, the intermediates (Retention Time 14.6 and 14.7) and the monoester (Retention Time 14.9) slowly converted into the diester (Retention Time 18.5). The conversion of 2,3-BDO and the formation of its esters upon the mole ratio 2,3-BDA:LA (1:3), at $80{ }^{\circ} \mathrm{C}$, are depicted in Figure 5A. The conversion of 2,3-BDO reached $97 \%$ after $2 \mathrm{~h}$. However, the yields of the monoester and diester were 24 and $25 \%$, respectively, at $80{ }^{\circ} \mathrm{C}$. The highest yield of the diester was achieved after $24 \mathrm{~h}(85 \%)$ and complete conversion of 2,3-BDO was observed. The catalyst BAIL-2 was successfully recycled in the lower phase but a trace amount of BAIL-2 was also observed in the upper phase by ${ }^{1} \mathrm{H}$ NMR spectra. Therefore, we used diethyl ether for complete recovery of the catalyst and reused it in the process multiple times (Figure 5B) without adding the fresh catalyst. Interestingly, the yield of the diester slightly improved in the second and third cycle ( 89.4 and $88 \%$, respectively) after $24 \mathrm{~h}$. However, a constant diester yield $(78.35 \%)$ was observed from the fourth to sixth cycle (Figure 5B), at complete conversion of 2,3-BDO.

2.7. Self-Induced Biphasic Separation of the Catalyst after Esterification. Among all the synthesized BAILs, only BAIL-2 was automatically phase separated after esterification in 2,3-BDO:LA (1:2) at $105{ }^{\circ} \mathrm{C}$ (Figure 6A). Even when higher molar excess of LA and lower temperature $\left(80{ }^{\circ} \mathrm{C}\right)$ were applied, automatic phase separation occurred (Figure 6A). The lower phase contained BAIL-2 and the upper phase the ester products, byproducts, and unreacted LA.
The upper phase moisture contained was $2.5 \mathrm{wt} \%$. It is noteworthy that BAIL-1 is miscible with the purified diester because of its anion moiety. On the contrary, BAIL-1, BAIL-3, and BAIL-4 were immiscible with the purified diester (Figure 6B). BAIL-3 and BAIL-4 were not good catalysts for diester formation as discussed above and the reason might be related to the fact that no phase separation occurred. Despite higher catalyst loading $(2.28 \mathrm{mmol})$, neither BAIL-3 nor BAIL-4 were phase separated.

\section{CONCLUSIONS}

As a summary, we demonstrated automatic phase separation of BAILs in esterification reaction of sugar liquors at low temperatures. The levulinate ester product could be useful upon blending with diesel as an oxygenated biofuel additive (similarly the di and tri-ester of glycerol with LA). One of the advantages is the reduced $\mathrm{SO}_{x}$ and $\mathrm{NO}_{x}$ formation. Complete conversion of 2,3-BDO and good yield (85\%) of the diester were obtained at $80{ }^{\circ} \mathrm{C}$ in $24 \mathrm{~h}$. The sulfonic acidfunctionalized pyridinium IL catalysts were successfully recycled and reused in the process. The high catalytic activity is likely thanks to their Brønsted acidity. Moreover, the water scavenging property of BAILs favor the equilibrium shift toward the products at low temperatures. Diesters of 2,3-BDO and LA could find use as plasticizers, solvents, and in other similar applications.

\section{EXPERIMENTAL SECTION}

4.1. Materials. LA (98\%), 2,3-butanediol (98\%, CAS Number 513-85-9), pyridine (98\%), 1,4-butane sultone, (98\%), trifluoromethanesulfonic acid, (97\%), $\mathrm{HCl}$ (37\%), $\mathrm{H}_{2} \mathrm{SO}_{4}$ (97\%), and Amberlyte IR-120 (H-form) were provided by Sigma-Aldrich. Ethyl acetate (99.5\%) was purchased from Fisher Scientific. All solvents (hexane, toluene, and diethyl ether) used were of ACS grade and used as received.

4.2. Methods. 4.2.1. Characterization. The synthesized BAILs and ester products were characterized by utilizing ${ }^{1} \mathrm{H}$ and ${ }^{13} \mathrm{C}$ NMR spectroscopy with Bruker AVANCE $400 \mathrm{MHz}$ NMR instruments. All the NMR spectra were assigned using Bruker's Topspin (4.0.6) processing software. The Hammett acidity functions of BAILs were determined using UV/vis spectroscopy (Cary 5000 UV-Vis-NIR spectrophotometer). The attenuated total reflectance-FT-IR spectroscopy (ATRFT-IR) technique was used for the analysis of functional groups before and after esterification of LA by a Bruker Vertex 80v FT-IR spectrometer (vacuum bench) with a DTGS 


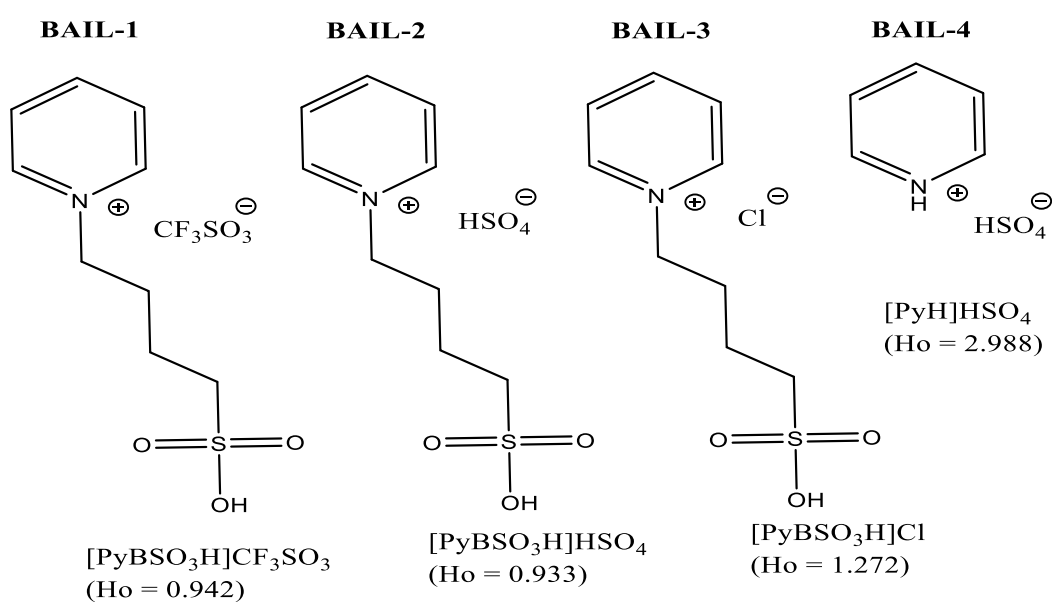

Figure 7. Molecular structures of synthesized ILs.

detector. The thermal stability of BAILs were analyzed by thermogravimetric analysis (TGA) by heating the samples under an Ar flow using a Netzsch STA 449 F3 Jupiter" (STA) instrument. All samples were heated from 25 to $500{ }^{\circ} \mathrm{C}$ with a heating rate of $10^{\circ} \mathrm{C} \mathrm{min}^{-1}$. The moisture contained in the BAILs was analyzed by Karl Fischer titration using a KFcoulometer (Metrohm). A gas chromatography-flame ionization detector (GC-FID) (Agilent $6890 \mathrm{~N}$ ) equipped with an HP-5 column was used for quantitative analysis of products.

4.2.2. Synthesis of BAILs. The BAILs (Figure 7) were synthesized according to the literature report with slight modifications. ${ }^{39}$ For the synthesis of BAILs, an equimolar amount of pyridine $(5 \mathrm{~g}, 63 \mathrm{mmol})$ and 1,4-butanesultone (8.6 $\mathrm{g}$, $63 \mathrm{mmol}$ ) were stirred at $40{ }^{\circ} \mathrm{C}$ for $6 \mathrm{~h}$, after which $10 \mathrm{~mL}$ toluene was added. The reaction mixture was continuously stirred at $100{ }^{\circ} \mathrm{C}$ for $12 \mathrm{~h}$. The toluene was evaporated and the zwitterionic precursor was washed three times using diethyl ether. The zwitterionic precursor was further mixed with a stoichiometric amount of $\mathrm{CF}_{3} \mathrm{SO}_{3} \mathrm{H}$ for preparation of 1-(4sulfonic) butyl pyridinium trifluoromethanesulfonate (BAIL1), $\mathrm{H}_{2} \mathrm{SO}_{4}$ for 1-(4-sulfonic) butyl pyridinium hydrogen sulfate (BAIL-2), and $\mathrm{HCl}$ for 1-(4-sulfonic) butyl pyridinium chloride (BAIL-3) in water and stirred overnight at room temperature. The resulting BAILs were washed with diethyl ether and dried under vacuum over a Schleck line. The obtained BAIL-1 and BAIL-2 were liquid, while BAIL-3 was a solid powder. The overall yield of BAILs were founded in the range of $75-80 \%$. The equimolar pyridine (three times diluted by $\mathrm{H}_{2} \mathrm{O}$ ) and $\mathrm{H}_{2} \mathrm{SO}_{4}$ (three times diluted by $\mathrm{H}_{2} \mathrm{O}$, exothermic reaction, be careful!) were slowly mixed under stirring at $5{ }^{\circ} \mathrm{C}$. The reaction mixture was stirred at room temperature for $2 \mathrm{~h}$. After this step, water was evaporated and the obtained pyridinium hydrogen sulfate was washed with diethyl ether. The yield of pyridinium hydrogen sulfate was 96\% (BAIL-4). The moisture content of all as synthesized BAILs were found in the range of $2-3$ wt $\%$ based on a Karl Fisher titration. The ${ }^{1} \mathrm{H}$ NMR of precursor molecules and synthesized BAILs were recorded. It was evident that the ${ }^{1} \mathrm{H}$ NMR spectra contained no undesirable peaks. The as prepared BAILs were pure and ready for use in the esterification reaction.

4.2.3. Characterization of BAILs. Figure 7 shows the molecular structure of ILs used in this study. The molecular structure of BAILs were confirmed from ${ }^{1} \mathrm{H}$ NMR (Figure S6). The chemical shift in proton NMR of BAILs was observed in the range of $0.05-0.4 \mathrm{ppm}$ after protonation and because of the influence of anions (Figure S6). After the quarterization of pyridine, the aromatic proton of the zwitter ion and BAILs was deshielded at higher ppm in the range of $0.2-1 \mathrm{ppm}$ from the original position of aromatic proton of pyridine as shown in Figure S7. The thermal stability of pyridinium-based BAILs varied depending on anions. The onset degradation temperature $\left(T_{\mathrm{d}}\right)$ of BAIL-1, BAIL-2, BAIL-3, and BAIL-4 were obtained at $310,285,280$, and $271{ }^{\circ} \mathrm{C}$, respectively (Figure S8). BAIL-1 and BAIL-2 were found in the liquid state at room temperature. BAIL-3 was found as glassy liquids below $100^{\circ} \mathrm{C}$. The differential scanning calorimetry (DSC) curve displayed the melting point of BAIL-3 at $133{ }^{\circ} \mathrm{C}$ (Figure S9). Similarly, the melting point of BAIL-4 was found to be $94{ }^{\circ} \mathrm{C}$. The Hammett acidity function $\left(H_{\mathrm{o}}\right)$ of BAILs was examined from $\mathrm{UV}$-vis spectroscopy using 4-nitroaniline as the probe. The $H_{\mathrm{o}}$ value of synthesized BAILs was in good agreement as literature reports. ${ }^{40}$ The variation of the $H_{\mathrm{o}}$ value also depends upon the concentration of BAILs. Here, we recorded the UV-vis spectra in methanol of the 4-nitroaniline probe and BAILs with the concentrations $7.5 \times 10^{-5}$ and $5 \times 10^{-2} \mathrm{~mol} \mathrm{~L}^{-1}$, respectively. The UV-vis spectra are given in Figure S10. The Hammett acidity function $\left(H_{\mathrm{o}}\right)$ is summarized in Table $S 1$. The Brønsted acidity decreased in this order $\mathrm{H}_{2} \mathrm{SO}_{4} \geq$ BAIL- $2 \approx$ BAIL- $1>$ BAIL-3 > BAIL-4. The Brønsted acidity of BAIL-1 $\left(H_{\mathrm{o}}=0.94\right)$ and BAIL-2 $\left(H_{\mathrm{o}}=0.93\right)$ were found comparable to $\mathrm{H}_{2} \mathrm{SO}_{4}\left(H_{\mathrm{o}}\right.$ $=0.90)$. Therefore, both BAILs were observed to be more efficient for esterification compared to BAIL-3 and BAIL-4.

4.2.4. Hammett Acidity of BAILs. The Hammett acidity function of BAILs were determined by spectroscopic techniques using a 4-nitroaniline probe $\left(\mathrm{p} K_{\mathrm{a}}=0.99\right)$ as per our previous report. ${ }^{41}$ This is useful information in terms of the estimation of Brønsted acidity of ILs. A basic probe was used as the trap of dissociative proton of BAILs in methanol. The probe solution was prepared in methanol having a concentration $\left(7.5 \times 10^{-5} \mathrm{~mol} \mathrm{~L}^{-1}\right)$, and the BAIL concentration $(5 \times$ $\left.10^{-2} \mathrm{~mol} \mathrm{~L}^{-1}\right)$ was added in the probe solution. The solution was stirred for $2 \mathrm{~h}$, after which the absorbance of solution was recorded. The Hammett acidity function $\left(H_{\mathrm{o}}\right)$ values of BAILs were calculated from eq 1 (Table S1).

$$
H_{\mathrm{o}}=\mathrm{p} K_{\mathrm{a}}+\log \left([\mathrm{I}] /\left[\mathrm{IH}^{+}\right]\right)
$$

where, $\mathrm{p} K_{\mathrm{a}}$ is the value of the indicator [I] corresponding to the molar concentration of the unprotonated form of the probe and $\left[\mathrm{IH}^{+}\right]$is the protonated form of the probe. A decreasing 
intensity of absorbance after protonation determined the $H_{\mathrm{o}}$ value.

4.2.5. General Procedure for Esterification of $L A$ with 2,3Butanediol. In a typical reaction, 2,3-BDO $(8.60 \mathrm{mmol}, 0.775$ $\mathrm{g})$ and two equivalents of LA $(17.22 \mathrm{mmol} 2.0 \mathrm{~g})$ were taken in a vial with a catalytic amount of BAILs $/ \mathrm{H}_{2} \mathrm{SO}_{4}(0.57 \mathrm{mmol})$. The reaction mixture was charged at different temperatures $\left(60-105{ }^{\circ} \mathrm{C}\right)$ in a preheated oil bath and samples were collected at predefined time intervals. The collected samples were diluted by ethyl acetate, neutralized using sodium bicarbonate and a small amount of sodium sulfate was used for removal of water. Samples were injected into GC for quantitative analysis. The conversion of 2,3-BDO, selectivity, and yield were calculated from the formula given below.

$$
\begin{aligned}
& \text { \% conversion }=\frac{C_{\mathrm{i}}-C_{\mathrm{f}}}{C_{\mathrm{f}}} \times 100 \\
& \% \text { selectivity }=\frac{C_{\mathrm{p}}}{C_{\mathrm{i}}-C_{\mathrm{f}}} \times 100 \\
& \% \text { yield }=\frac{C_{\mathrm{p}}}{C_{\mathrm{i}}} \times 100
\end{aligned}
$$

where $C_{\mathrm{i}}$ and $C_{\mathrm{f}}$ are the initial and final concentration (mmol) of 2,3-BDO and $C_{\mathrm{p}}$ is concentration of ester products.

4.2.6. Purification and Separation of the Diester/ Monoester. The upper phase ester products and unreacted LA of the reaction mixture were subjected to separation of the monoester and diester in order to obtain pure products. A slurry (silica with ester products) was packed in a silica column and the mixture of hexane and ethyl acetate was used as a solvent with an increasing volume $(5,10,15,20 \mathrm{vol} \%)$ used to separate and concentrate the monoester and diester. However, the monoester and diester collectively eluded in the mixture of hexane with 15 vol \% ethyl acetate. As the next step, a liquidliquid extraction method was used to separate the monoester and diester by washing with ethyl acetate and $0.1 \mathrm{M}$ aqueous $\mathrm{NaCl}$ solution several times at room temperature. The aqueous phase monoester was extracted by increasing the concentration of $(5 \mathrm{M}) \mathrm{NaCl}$. The extracted products were dried by rotary evaporation and finally in a Schlenk line at $50{ }^{\circ} \mathrm{C}$ for $5 \mathrm{~h}$. The ${ }^{1} \mathrm{H}$ and ${ }^{13} \mathrm{C}$ NMR spectra were recorded of obtained products. The NMR peaks confirmed the formation of the diester and monoester product (Figure 1 and Figure S2c,d).

4.2.7. Products Analysis and Calibration Curve. The purified monoester and diester products were injected in GCFID using ethyl acetate as a solvent, whereupon the purity of the monoester and diester was found to be 95 and $95.7 \%$, respectively. The calibration curves of both esters were obtained using different concentrations. The products were quantitatively analyzed by GC-FID (Agilent $6890 \mathrm{~N}$ ) equipped with an HP-5 column (30 m length, $0.32 \mathrm{~mm}$ internal diameter, and $0.25 \mathrm{~m}$ of film thickness). Helium was used as the carrier gas. The GC injection port and the detector temperature were set at $250{ }^{\circ} \mathrm{C}$. The following temperature program was used for the analysis: initial column temperature was fixed at $50{ }^{\circ} \mathrm{C}$. First, the program was set with a rate of 4.5 ${ }^{\circ} \mathrm{C} \min ^{-1}$ up to $100{ }^{\circ} \mathrm{C}$ for no holding time. Second, the program was set from 100 to $300{ }^{\circ} \mathrm{C}$ with a rate of $20{ }^{\circ} \mathrm{C}$ $\mathrm{min}^{-1}$ and held at this temperature for $7 \mathrm{~min}$.

\section{ASSOCIATED CONTENT}

\section{Supporting Information}

The Supporting Information is available free of charge at https://pubs.acs.org/doi/10.1021/acsomega.9b03517.

Characterization of C-14 levulinate ester, monoester, and acidic ILs; NMR spectrum; FT-IR spectra; calibration curve of ester products by GC; LC-MS chromatogram; TGA, DSC, and Hammett acidity of ILs; yield of ester products in a close system (PDF)

\section{AUTHOR INFORMATION}

\section{Corresponding Authors}

Chandrakant Mukesh - Technical Chemistry, Department of Chemistry, Chemical-Biological Centre, Umeå University, SE90187 Umeå, Sweden; (i) orcid.org/0000-0003-4097-3504; Phone: +46-734826184; Email: chandrakant.mukesh@ umu.se, chandrakantmukesh2009@gmail.com

Jyri-Pekka Mikkola - Technical Chemistry, Department of Chemistry, Chemical-Biological Centre, Umeå University, SE90187 Umeå, Sweden; Industrial Chemistry \& Reaction Engineering, Department of Chemical Engineering, Johan Gadolin Process Chemistry Centre, Åbo Akademi University, FI20500 Åbo-Turku, Finland; Phone: +46-706200371; Email: jyri-pekka.mikkola@umu.se, jyri-pekka.mikkola@ abo.fi

\section{Author}

Dariush Nikjoo - Division of Material Science, Luleå University of Technology, SE-97187 Luleå, Sweden

Complete contact information is available at:

https://pubs.acs.org/10.1021/acsomega.9b03517

\section{Notes}

The authors declare no competing financial interest.

\section{ACKNOWLEDGMENTS}

This work is part of activities of the Technical Chemistry, Department of Chemistry, Chemical Biological Centre, Umeå University, Sweden and the Johan Gadolin Process Chemistry Centre at Åbo Akademi University in Finland. The Bio4Energy programme, Kempe Foundations, and Wallenberg Wood Science Center under auspices of Alice and Knut Wallenberg Foundation are gratefully acknowledged for funding this project.

\section{REFERENCES}

(1) Meyers, J.; Mensah, J. B.; Holzhäuser, F. J.; Omari, A.; Blesken, C. C.; Tiso, T.; Palkovits, S.; Blank, L. M.; Pischinger, S.; Palkovits, R. Electrochemical Conversion of a Bio-Derivable Hydroxy Acid to a Drop-in Oxygenate Diesel Fuel. Energy Environ. Sci. 2019, 12, 24062411.

(2) Climent, M. J.; Corma, A.; Iborra, S. Conversion of Biomass Platform Molecules into Fuel Additives and Liquid Hydrocarbon Fuels. Green Chem. 2014, 16, 516-547.

(3) Morone, A.; Apte, M.; Pandey, R. A. Levulinic Acid Production from Renewable Waste Resources: Bottlenecks, Potential Remedies, Advancements and Applications. Renew. Sustain. Energy Rev. 2015, 51, 548-565.

(4) Fitzpatrick, S. W. The Biofine Technology: A "Bio-Refinery" Concept Based on Thermochemical Conversion of Cellulosic Biomass. ACS Symp. Ser. 2006, 921, 271-287.

(5) Chen, Z.; Bai, X.; A, L.; Wan, C. High-Solid Lignocellulose Processing Enabled by Natural Deep Eutectic Solvent for Lignin 
Extraction and Industrially Relevant Production of Renewable Chemicals. ACS Sustainable Chem. Eng. 2018, 6, 12205-12216.

(6) Baek, J.; Kim, T. Y.; Kim, W.; Lee, H. J.; Yi, J. Selective Production of 1,3-Butadiene Using Glucose Fermentation Liquor. Green Chem. 2014, 16, 3501-3507.

(7) Celińska, E.; Grayek, W. Biotechnological Production of 2,3Butanediol-Current State and Prospects. Biotechnol. Adv. 2009, 27, $715-725$.

(8) Xiu, Z.-L.; Zeng, A.-P. Present State and Perspective of Downstream Processing of Biologically Produced 1,3-Propanediol and 2,3-Butanediol. Appl. Microbiol. Biotechnol. 2008, 78, 917-926.

(9) Démolis, A.; Essayem, N.; Rataboul, F. Synthesis and Applications of Alkyl Levulinates. ACS Sustainable Chem. Eng. 2014, 2, 1338-1352.

(10) Ahmad, E.; Alam, M. I.; Pant, K. K.; Haider, M. A. Catalytic and Mechanistic Insights into the Production of Ethyl Levulinate from Biorenewable Feedstocks. Green Chem. 2016, 18, 4804-4823.

(11) Xu, Y.; Hakkarainen, M.; Odelius, K. Levulinic Acid as a Versatile Building Block for Plasticizer Design. ACS Sustainable Chem. Eng. 2019, 7, 13456-13463.

(12) Quereshi, S.; Ahmad, E.; Pant, K. K.; Dutta, S. Insights into the Metal Salt Catalyzed Ethyl Levulinate Synthesis from Biorenewable Feedstocks. Catal. Today 2017, 291, 187-194.

(13) Pileidis, F. D.; Titirici, M. M. Levulinic Acid Biorefineries: New Challenges for Efficient Utilization of Biomass. ChemSusChem 2016, 9, 652-655.

(14) Badgujar, K. C.; Wilson, L. D.; Bhanage, B. M. Recent Advances for Sustainable Production of Levulinic Acid in Ionic Liquids from Biomass: Current Scenario, Opportunities and Challenges. Renew. Sustain. Energy Rev. 2019, 102, 266-284.

(15) Texaco/NYSERDA/Biofine. Ethyl Levulinate D-975 Diesel Additive Test Program; Glenham: New York, 2000.

(16) Fernando, S.; Hall, C.; Jha, S.; Jha, S. NOx Reduction from Biodiesel Fuels. Energy Fuels 2006, 20, 376-382.

(17) Joshi, H.; Moser, B. R.; Toler, J.; Smith, W. F.; Walker, T. Ethyl Levulinate: A Potential Bio-Based Diluent for Biodiesel Which Improves Cold Flow Properties. Biomass Bioenergy 2011, 35, 32623266.

(18) Huang, Z.; Lu, H.; Jiang, D.; Zeng, K.; Liu, B.; Zhang, J.; Wang, $\mathrm{X}$. Performance and Emissions of a Compression Ignition Engine Fueled with Diesel/Oxygenate Blends for Various Fuel Delivery Advance Angles. Energy Fuels 2005, 19, 403-410.

(19) Yanfeng, G.; Shenghua, L.; Hejun, G.; Tiegang, H.; Longbao, Z. A New Diesel Oxygenate Additive and its Effects on Engine Combustion and Emissions. Appl. Therm. Eng. 2007, 27, 202-207.

(20) Wang, Z.-w.; Lei, T. Z.; Liu, L.; Zhu, J. L.; He, X. F.; Li, Z. F. Performance Investigations of a Diesel Engine Using Ethyl LevulinateDiesel Blends. BioResources 2012, 7, 5972-5982.

(21) Windom, B. C.; Lovestead, T. M.; Mascal, M.; Nikitin, E. B.; Bruno, T. J. Advanced Distillation Curve Analysis on Ethyl Levulinate as a Diesel Fuel Oxygenate and a Hybrid Biodiesel Fuel. Energy Fuels 2011, 25, 1878-1890.

(22) Christensen, E.; Williams, A.; Paul, S.; Burton, S.; McCormick, R. L. Properties and Performance of Levulinate Esters as Diesel Blend Components. Energy Fuels 2011, 25, 5422-5428.

(23) Leng, Y.; Wang, J.; Zhu, D.; Ren, X.; Ge, H.; Shen, L. Heteropolyanion-Based Ionic Liquids: Reaction-Induced Self-Separation Catalysts for Esterification. Angew. Chem., Int. Ed. 2009, 48, 168171.

(24) Vafaeezadeh, M.; Alinezhad, H. Brønsted Acidic Ionic Liquids: Green Catalysts for Essential Organic Reactions. J. Mol. Liq. 2016, 218, 95-105.

(25) Tao, D.-J.; Lu, X.-M.; Lu, J.-F.; Huang, K.; Zhou, Z.; Wu, Y.-T. Noncorrosive Ionic Liquids Composed of [HSO4] as Esterification Catalysts. Chem. Eng. J. 2011, 171, 1333-1339.

(26) Ma, Y.; Han, F.; Li, Z.; Xia, C. Acidic-Functionalized Ionic Liquid as Corrosion Inhibitor for 304 Stainless Steel in Aqueous Sulfuric Acid. ACS Sustainable Chem. Eng. 2016, 4, 5046-5052.
(27) Saravanamurugan, S.; Van Buu, O. N.; Riisager, A. Conversion of Mono- and Disaccharides to Ethyl Levulinate and Ethyl Pyranoside with Sulfonic Acid-Functionalized Ionic Liquids. ChemSusChem 2011, 4, 723-726.

(28) Han, X.-X.; Du, H.; Hung, C.-T.; Liu, L.-L.; Wu, P.-H.; Ren, D.H.; Huang, S.-J.; Liu, S.-B. Syntheses of Novel Halogen-Free Brønsted-Lewis Acidic Ionic Liquid Catalysts and Their Applications for Synthesis of Methyl Caprylate. Green Chem. 2015, 17, 499-508.

(29) Kalghatgi, S. G.; Bhanage, B. M. Green Syntheses of Levulinate Esters Using Ionic Liquid 1-Methyl Imidazolium Hydrogen Sulphate [MIM][HSO4] in Solvent Free System. J. Mol. Liq. 2019, 281, 7080 .

(30) Kohno, Y.; Makino, T.; Kanakubo, M. Control of Phase Separation Behaviour of Ionic Liquid Catalysts with Reactants/ Products Toward Synthesis of Long-Chain Wax Esters at Moderate Temperatures. React. Chem. Eng. 2019, 4, 627-633.

(31) Voloch, M.; Jansen, N. B.; Ladisch, M. R.; Tsao, G. T.; Narayan, R.; Rodwell, V. W. 2,3-Butanediol. In Comprehensive Biotechnology; Moo-Young, M., Cooney, C. L., Humphrey, A. E., Eds.; Pergamon/Elsevier: Oxford, 1985; pp 933-947.

(32) Richard, R.; Guillaume, D.; Jacquin, M. Kinetics Modeling of the Heterogeneously Catalyzed Esterification of 2,3-Butanediol with Acetic Acid. Ind. Eng. Chem. Res. 2016, 55, 5247-5256.

(33) Gonzalez-Arellano, C.; Arancon, R. A. D.; Luque, R. Al-SBA-15 Catalysed Cross-Esterification and Acetalisation of Biomass-Derived Platform Chemicals. Green Chem. 2014, 16, 4985-4993.

(34) Mallesham, B.; Govinda Rao, B.; Reddy, B. M. Production of Biofuel Additives by Esterification and Acetalization of Bioglycerol. C. R. Chim. 2016, 19, 1194-1202.

(35) Delgado, P. J. ES 2201894 B2, 2002.

(36) Chiappe, C.; Rajamani, S.; D’Andrea, F. A Dramatic Effect of the Ionic Liquid Structure in Esterification Reactions in Protic Ionic Media. Green Chem. 2013, 15, 137-143.

(37) Zhang, W.; Yu, D.; Ji, X.; Huang, H. Efficient Dehydration of Bio-Based 2,3-Butanediol to Butanone Over Boric Acid Modified HZSM-5 Zeolites. Green Chem. 2012, 14, 3441-3450.

(38) Zhao, J.; Yu, D.; Zhang, W.; Hu, Y.; Jiang, T.; Fu, J.; Huang, H. Catalytic Dehydration of 2,3-Butanediol Over P/HZSM-5: Effect of Catalyst, Reaction Temperature and Reactant Configuration on Rearrangement Products. RSC Adv. 2016, 6, 16988-16995.

(39) Shinde, S. H.; Rode, C. V. A Two-Phase System for the Clean and High Yield Synthesis of Furylmethane Derivatives Over- $\mathrm{SO}_{3} \mathrm{H}$ Functionalized Ionic Liquids. Green Chem. 2017, 19, 4804-4810.

(40) Kondamudi, K.; Elavarasan, P.; Dyson, P. J.; Upadhyayula, S. Alkylation of p-Cresol with Tert-Butyl Alcohol Using Benign Bronsted Acidic Ionic Liquid Catalyst. J. Mol. Catal. A: Chem. 2010, 321, 34-41.

(41) Mukesh, C.; Mondal, D.; Sharma, M.; Prasad, K. Choline Chloride-Thiourea, a Deep Eutectic Solvent for the Production of Chitin Nanofibers. Carbohydr. Polym. 2014, 103, 466-471. 